\title{
Atividade antimicrobiana do extrato de (Allium sativum, Liliaceae) in natura e do extrato aquoso frente Candida albicans, Staphylococcus aureus e Streptococcus
} pyogenes

Antimicrobial activity of garlic (Allium sativum, Liliaceae) in nature and aqueous extract against Candida albicans, Staphylococcus aureus and Streptococcus pyogenes

Actividad antimicrobiana del ajo (allium sativum, Liliaceae) en la naturaleza y del extracto acuoso contra Candida albicans, Staphylococcus aureus y Streptococcus pyogenes

Recebido: 17/05/2021 | Revisado: 27/05/2021 | Aceito: 31/05/2021 | Publicado: 15/06/2021

\author{
Rayssa Rosendo Alves \\ ORCID: https://orcid.org/0000-0003-3638-167X \\ Centro Universitário São Miguel, Brasil \\ E-mail: rayssa15.ra76@gmail.com \\ Beatriz Rayana Damásio de Andrade \\ ORCID: https://orcid.org/0000-0002-1454-344X \\ Universidade Federal Rural de Pernambuco, Brasil \\ E-mail: beatrizdamasio54@gmail.com \\ Athila da Costa Silva \\ ORCID: https://orcid.org/0000-0003-0991-8726 \\ Centro Universitário São Miguel, Brasil \\ E-mail: Athiladacosta@gmail.com \\ Maria Luiza Ribeiro Bastos da Silva \\ ORCID: https://orcid.org/0000-0002-8406-9472 \\ Centro Universitário São Miguel, Brasil \\ E-mail: luizabastos6@yahoo.com.br
}

\begin{abstract}
Resumo
Introdução: O alho (Allium sativum) é pertencente à família Liliaceae, seu conhecimento popular se dar principalmente pela sua utilização na culinária, porém existem diversas alternativas de utilização medicinal, sendo desta forma pesquisado como alternativa natural e eficaz contra diversos microrganismos patogênicos. Sua eficiência foi evidenciada como antifúngica, antibacteriana, antiviral e antiparasitária. Objetivo: avaliar a atividade antimicrobiana do alho (Allium sativum), in natura e do extrato aquoso, frente ao fungo Candida albicans, e as bactérias Staphylococcus aureus ATCC 25923 e Streptococcus pyogene 1033B. Método: Trata-se de uma pesquisa experimental com abordagem quantitativa sobre a avaliação da atividade antimicrobiana do extrato de alho (Allium sativum, Liliaceae), in natura, e extrato aquoso de alho. Foi utilizado o método Difusão em Agar- técnica do Disco e do Poço em meio Ágar Mueller Hinton contendo os microrganismos testados, os poços e os discos de papeis filtro contendo os extratos. A obtenção do extrato in natura foi através da maceração e o extrato aquoso foi obtido através da imersão do alho em Cloreto de Sódio a 0,9\% durante 24 horas por sete dias. Resultados: Os resultados numéricos obtidos através da medição dos halos após o Teste de Disco e do Poço mostraram que o extrato aquoso não inibiu o crescimento dos microrganismos, enquanto o extrato in natura através do teste de disco, obteve resultado significativo frente S. aureus, S. pyogenes e C. albicans, possuindo halo de inibição de 23,3 $\pm 0,6,20 \pm 2$ e $18 \pm 0$ respectivamente. $\mathrm{Na}$ técnica do poço os halos para S. aureus, S. pyogenes e Candida albicans, foram de 41,3 0 0,6, $32 \pm 2$ e $24 \pm 0,6$ respectivamente. Conclusão: Conclui-se que o estudo Corrobora na comprovação da ação antimicrobiana do alho e mostra que o halo de inibição do extrato in natura tanto em $S$. aureus como em $S$. pyogenes foi superior ao halo dos antibióticos testados, o halo apresentado em Candida albicans também foi considerável e maior que o apresentado pelo antifúngico, mostrando desta forma como os microrganismos estão sensíveis ao extrato in natura do alho em comparação a os antibióticos comumente utilizados.
\end{abstract}

Palavras-chave: Antimicrobiano; Alicina; Resistência bacteriana.

\begin{abstract}
Introduction: Garlic (Allium sativum) belongs to the Liliaceae family, its popular knowledge is mainly due to its use in cooking, but there are several alternatives for medicinal use, being researched as a natural and effective alternative against various pathogenic microorganisms. Its efficiency has been evidenced as antifungal, antibacterial, antiviral and antiparasitic. Objective: To evaluate the antimicrobial activity of garlic (Allium sativum), in natura and the
\end{abstract}


aqueous extract, against the fungus Candida albicans, and the bacteria Staphylococcus aureus ATCC 25923 and Streptococcus pyogene 1033B. Method: This is an experimental research with quantitative approach on the evaluation of the antimicrobial activity of garlic extract (Allium sativum, Liliaceae), in natura, and aqueous garlic extract. The agar diffusion method was used - Disc and Well technique in Mueller Hinton Agar medium containing the tested microorganisms, the wells and the filter paper discs containing the extracts. The raw extract was obtained by maceration and the aqueous extract was obtained by soaking the garlic in $0.9 \%$ Sodium Chloride for 24 hours for seven days. Results: The numerical results obtained by measuring the halos after the Disc and Well Test showed that the aqueous extract did not inhibit the growth of microorganisms, while the in natura extract through the disc test, obtained significant result against S. aureus, S. pyogenes and C. albicans, possessing halo of inhibition of $23.3 \pm 0.6$, $20 \pm 2$ and $18 \pm 0$ respectively. In the well technique, the halos for S. aureus, S. pyogenes and Candida albicans, were $41.3 \pm 0.6,32 \pm 2$ and $24 \pm 0.6$ respectively. Conclusion: It is concluded that the study corroborates in the proof of the antimicrobial action of garlic and shows that the halo of inhibition of the extract in natura both in S. aureus as in S. pyogenes was superior to the halo of the antibiotics tested, the halo presented in Candida albicans was also considerable and bigger than the one presented by the antifungal, showing this way how the microorganisms are sensitive to the extract in natura of garlic in comparison to the antibiotics commonly used.

Keywords: Antimicrobial; Allicin; Bacterial resistance.

\section{Resumen}

Introducción: El ajo (Allium sativum) pertenece a la familia de las Liliáceas, su conocimiento popular está dado principalmente por su uso en la cocina, pero existen varias alternativas de uso medicinal, siendo investigado como una alternativa natural y efectiva contra diversos microorganismos patógenos. Se evidenció su eficacia como antifúngico, antibacteriano, antiviral y antiparasitario. Objetivo: Evaluar la actividad antimicrobiana del ajo (Allium sativum), in natura y del extracto acuoso, contra el hongo Candida albicans, y las bacterias Staphylococcus aureus ATCC 25923 y Streptococcus pyogene 1033B. Método: Se trata de una investigación experimental con enfoque cuantitativo sobre la evaluación de la actividad antimicrobiana del extracto de ajo (Allium sativum, Liliaceae), in natura, y del extracto acuoso de ajo. Se utilizó el método de difusión en agar - técnica de discos y pozos en el medio de Agar Mueller Hinton que contenía los microorganismos analizados, los pozos y los discos de papel de filtro que contenían los extractos. El extracto in natura se obtuvo por maceración y el extracto acuoso se obtuvo sumergiendo el ajo en cloruro de sodio al 0,9\% durante 24 horas durante siete días. Resultados: Los resultados numéricos obtenidos mediante la medición de los halos tras el Test del Disco y del Pozo mostraron que el extracto acuoso no inhibió el crecimiento de los microorganismos, mientras que el extracto in natura mediante el test del disco, obtuvo un resultado significativo contra S. aureus, S. pyogenes y C. albicans, poseyendo halos de inhibición de 23,3 $\pm 0,6,20 \pm 2$ y $18 \pm 0$ respectivamente. En la técnica de pozos los halos para S. aureus, S. pyogenes y Candida albicans, fueron de $41,3 \pm$ 0,6, $32 \pm 2$ y $24 \pm 0,6$ respectivamente. Conclusión: Se concluye que el estudio corrobora la prueba de la acción antimicrobiana del ajo y muestra que el halo de inhibición del extracto in natura tanto en S. aureus como en S. pyogenes fue mayor que el halo de los antibióticos ensayados, el halo presentado en Candida albicans también fue considerable y mayor que el presentado por los antifúngicos, mostrando así lo sensibles que son los microorganismos al extracto in natura de ajo en comparación con los antibióticos de uso común.

Palabras clave: Antimicrobiano; Alicina; Resistencia bacteriana.

\section{Introdução}

O alho (Allium sativum) é pertencente à família Liliaceae, seu conhecimento popular se dar principalmente pela sua utilização na culinária, porém existem diversas alternativas de utilização medicinal, sendo desta forma pesquisado como alternativa natural e eficaz contra diversos microrganismos patogênicos (Ferreira et al., 2016). Sua eficiência foi evidenciada como antifúngica, antibacteriana, antiviral e antiparasitário (Johnson, Olaleye \& Kolawole, 2016).

O princípio ativo responsável por esses benefícios é a Alicina que possui grande atividade contra os microrganismos (Ferreira et al.,2016). Em 1944 Cavallito e Bailey realizaram estudos relacionados à ação da alicina no retardo do crescimento bacteriano, porém as culturas antigas já acreditavam que o alho era benéfico à saúde (Gonçalves et al., 2015). Pois a utilização das plantas para tratamento, cura e prevenção de doenças é realizado desde a antiguidade (Moreno, 2019).

O Brasil, que é um país rico em cobertura vegetal e também em virtude da sua diversidade cultural tem como prática comum o uso de fitoterápicos e plantas medicinais em diversos tratamentos (Lima-Saraiva et al., 2015). Diante disso, várias alternativas a base de plantas e extratos vegetais têm sido testados na intenção de substituírem os antibióticos sintéticos que são grandes contribuintes da resistência bacteriana (Caldas et al., 2019). 
Em função dessa resistência dos microrganismos aos antibióticos circulantes no mercado, tem-se elevado cada vez mais a busca necessária por alternativas eficazes no tratamento desses patógenos (Felix, Medeiros \& Medeiros, 2018). Diante dessa problemática, a busca se direciona para alternativas que contribuam no desenvolvimento da saúde, sendo eficaz, menos tóxicas e principalmente a base de fontes naturais (Silva et al., 2019).

Para a realização de estudos científicos são utilizadas preferencialmente bactérias patogênicas e de importância médica, tais como Staphylococcus aureus e Streptococcus pyogenes (Dutra et al., 2016).O S. aureus foi uma das primeiras bactérias a ser tratada com o advento da descoberta dos antibióticos e também é componente da microbiota humana, podendo causar de infecções simples a graves, por possui uma capacidade adaptativa considerável e resistência à maioria os antibióticos e por ser a mais virulenta do seu gênero deve receber atenção médica e científica cabível (Lima et al., 2015; Santos et al., 2007). Dentre as infecções mais graves causadas pelo S. aureus pode-se citar: infecções cutâneas, no trato urinário, no pulmão e que podem chegar a sepse (Salem et al., 2016). A sepse bacteriana é uma problemática preocupante na saúde, pois é uma das maiores causas de morte em pacientes hospitalizados (Qin et al.,2017).

O S. pyogenes possui um potencial virulento alto, atinge os humanos e causa infecções leves ou infecções graves, também pode ser transmitida por pessoas assintomáticas. Para pacientes com predisposição muitas vezes o patógeno é fatal, o que acarreta num número considerável de vítimas, conferindo-lhe uma relevância significativa (Fiedler et al., 2015). Como suas infecções graves, pode-se exemplificar: fasceíte necrosante e síndrome do choque tóxico estreptocócico que são fatais (Brouwer et al., 2016).

Outro patógeno de importância médica é a Candida ssp. que é responsável por cerca de $80 \%$ das infecções fúngicas no âmbito hospitalar, além de ser causa relevante nas infecções da corrente sanguínea. Dentro dessas infecções, ao menos 50\% são causadas pelas espécies não-albicans. A infecção por esse fungo é um desafio clinico em diversos países, haja vista a taxa de mortalidade geral de fungemias por Candida spp. que está entre 40 e $60 \%$ (Colombo \& Guimarões, 2003)

Estudos foram realizados para se testar o potencial de inibição do alho sobre alguns microrganismos. Como resultado observou-se que o extrato fresco do alho in natura apresenta uma considerável atividade antimicrobiana frente os organismos Candida albicans, S. aureus, e E. coli (Milani et al., 2016; Fonseca et al., 2014). Observou-se também que o extrato aquoso do alho associado a antibióticos tem um fator de inibição considerável frente cepas de S. aureus (Machado et al., 2019). Levando em consideração esses resultados positivos de inibição o alho é uma ótima alternativa para um antimicrobiano, podendo substituir o uso de antibióticos que por sua vez, também trazem efeitos colaterais. Sabendo a importância baseada no uso da ação antimicrobiana do alho, foi objetivado avaliar a ação do alho in natura e do extrato aquoso em comparação ao antibiótico e antifúngico em cepas do fungo Candida albicans, e das bactérias S. pyogenes e S. aureus.

\section{Metodologia}

A pesquisa foi um estudo experimental com uma abordagem quantitativa (Fonseca et al., 2014) da atividade antimicrobiana do alho (Allium sativum) in natura e do seu extrato aquoso frente ao fungo Candida albicans, e as bactérias Staphylococcus aureus ATCC 25923 e S. pyogene 1033B. O estudo foi realizado no Laboratório de Microbiologia do Centro Universitário São Miguel (UNISÃOMIGUEL), Recife-PE.

Para a utilização do alho in natura e do extrato aquoso foram adquiridos em supermercado cerca de 15 bulbos de Allium sativum, os quais na medida em que eram utilizados foram descascados e imersos por 10 minutos em solução de hipoclorito de sódio (NaClO) a 2,5\% para esterilização. Para os testes in natura, 35g do bulbilho do alho foi macerado no almofariz de porcelana com a ajuda de um pistilo e a sua massa espremida com o auxílio de gaze estéril e um espremedor em um almofariz de porcelana menor para assim se obter o estrato bruto in natura, sendo todos os materiais utilizados para extração autoclavados por 1 hora (Milani et al., 2016). O extrato aquoso a 170\% foi obtido a partir da imersão do bulbilho em 
$10 \mathrm{~mL}$ de solução fisiológica (Cloreto de Sódio a $0,9 \%$ ) durante 24 horas, diariamente sendo retirado o bulbilho antigo e inserido um novo bulbilho na mesma solução, por sete dias, o peso total de alho utilizado para o extrato aquoso foi de $17 \mathrm{~g}$ (Fonseca et al., 2014).

Foram preparados $600 \mathrm{~mL}$ de meio de cultura Ágar Mueller Hinton, distribuídos em 20 placas de Petri descartáveis medindo 90 x 15 mm onde foram inoculados $20 \mu 1$ de cada microrganismo diluído em solução salina a $0,9 \%$ e com turvação de 0.5 na escala McFarland, os inóculos foram distribuídos em toda superfície da placa utilizando swab estéril.

A Técnica de Disco-difusão foi realizada utilizando discos de papel filtro autoclavados medindo $6 \mathrm{~mm}$ de diâmetro que foram postos com auxílio de uma pinça estéril em uma placa de Petri e inoculados os extratos, 06 discos embebidos com $20 \mu \mathrm{L}$ do extrato bruto do alho in natura, e outros 06 discos receberam $20 \mu \mathrm{L}$ do extrato aquoso. A técnica do Poço- difusão foi realizada com a perfuração de 09 poços medindo $6 \mathrm{~mm}$ e depositados $50 \mu \mathrm{l}$ de extrato bruto do alho in natura, e 09 poços com $50 \mu 1$ do extrato aquoso, sendo feitos 2 poços por placa. Foram utilizados também discos de antimicrobiano como referência para a análise dos dados, sendo Novobiocina para S. aureus, Bacitracina para S. pyogenes e Clorexidina para Candida albicans.

Em cada placa inseriu-se um disco contendo extrato aquoso, um disco contendo extrato in natura e um disco do respectivo antibiótico. Para a técnica do poço, foram feitos dois poços um contendo extrato in natura e outro contendo extrato aquoso. As placas foram incubadas em estufa a $37^{\circ} \mathrm{C}$ durante 24 horas. Ao final do processo foram observados os halos de inibição de crescimento bacteriano e os mesmos medidos utilizando régua milimetrada.

O experimento foi realizado em triplicata e o resultado expresso em milímetro através da média do diâmetro dos halos de cada repetição. Os dados foram analisados a partir da leitura das placas e interpretação dos resultados em sensível, intermediário ou resistente e, por fim, os resultados numéricos foram expressos em uma tabela contendo a média \pm erro padrão da média e a significância avaliada pela analise de variância ANOVA sendo $p<0,05$ considerado como diferencia significativa.

\section{Resultados e Discussão}

Os resultados da ação inibitória dos extratos de alho foram obtidos através da interpretação do Teste de Sensibilidade a Antimicrobianos, sendo que o extrato aquoso não apresentou nenhum tipo de atividade frente os microrganismos testados. O extrato in natura obteve resultado significativo sobre as cepas, sedo S. aureus sensível, S.pyogenes sensível e Candida albicans sensível (Quadro 1). Essa interpretação foi feita com base nos estudos de Ostrosky et al. (2008) onde os halos de inibição devem ser maior ou não ultrapassar de $3 \mathrm{~mm}$ menor que o controle positivo para ser considerado sensível, halo ultrapassando $2 \mathrm{~mm}$, porém mais de $3 \mathrm{~mm}$ maior que o controle positivo para ser moderadamente sensível e diâmetro menor ou igual a $2 \mathrm{~mm}$ para ser resistente.

Quadro1 - Relação dos microrganismos testados quanto a sua sensibilidade aos extratos comparando ao controle.

\begin{tabular}{|c|c|c|}
\hline Bactérias testadas & Extrato do alho in natura & Extrato aquoso \\
\hline Staphylococcus aureus ATCC 25923 & Sensível & Sem atividade \\
\hline Streptococcus pyogenes 1033B & Sensível & Sem atividade \\
\hline Candida albicans & Sensível & Sem atividade \\
\hline
\end{tabular}

Fonte: Autores.

Os resultados numéricos obtidos através da medição dos halos após o Teste de Disco e do Poço mostraram que o extrato aquoso não inibiu o crescimento dos microrganismos, enquanto o extrato in natura através do teste de disco, obteve 
resultado significativo frente S. aureus, S. pyogenes e C. albicans, possuindo halo de inibição de 23,3 $\pm 0,6,20 \pm 2$ e $18 \pm 0$ respectivamente. Na técnica do poço os halos para S. aureus, S. pyogenes e Candida albicans, foram de 41,3 $\pm 0,6,32 \pm 2 \mathrm{e}$ $24 \pm 0,6$ respectivamente, como é expresso na Tabela 2 e nas Figuras 1 e 2 .

Tabela 1 - Diâmetro dos halos de inibição de crescimento de Candida albicans, S. aureus e S. pyogenes frente aos Extratos aquoso e in natura do alho e dos antibióticos de controle, pelo método de Disco e do poço.

\begin{tabular}{ccccc}
\hline & Média \pm SEM do halo de inibição (mm) & & \\
\hline Microrganismos testados & Controle & $\begin{array}{c}\text { Extrato do alho in } \\
\text { natura (Disco) }\end{array}$ & $\begin{array}{c}\text { Extrato do alho natura (Poço) } \\
\text { aquoso do } \\
\text { alho }\end{array}$ & $\begin{array}{c}\text { Extrato } \\
\text { Staphylococcus aureus ATCC 25923 }\end{array}$ \\
\hline Streptococcus pyogenes 1033B & $12,6 \pm 6,5^{\mathrm{I}}$ & $23,3 \pm 0,6$ & $41,3 \pm 0,6$ & 0 \\
\hline Cândida albicans & $16 \pm 2^{\mathrm{II}}$ & $20 \pm 2$ & $32 \pm 2$ & 0 \\
\hline
\end{tabular}

Controle: $\mathrm{I}=$ Novobiocina, $\mathrm{II}=$ Bacitracina e III = Clorexidina. ANOVA estatisticamente significativo frente ao do controle positivo $\mathrm{p}<0,003$.

Fonte: Autores.

Figura 1 - Teste em $S$. aureus - Disco

Figura 2 - Teste em S. aureus - Poço.
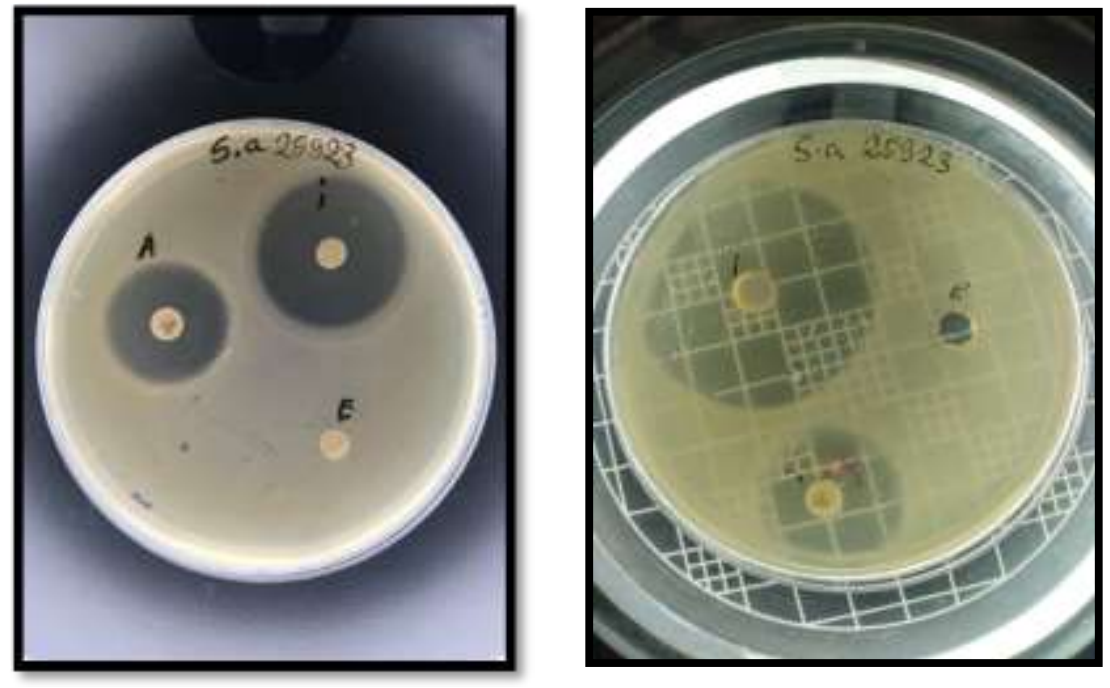

Fonte: Autores.

Para Felix, Medeiros e Medeiros (2018) os diferentes tipos de extratos, concentrações e microrganismos testados influenciam de forma significativa nos resultados, motivo pelo qual alguns não são satisfatórios. O estudo de Grosso et al. (2013) concluem que o extrato bruto de alho independente da concentração possui atividade inibitória contra S. aureus, o que é também evidenciado nesse trabalho. Ainda em estudos mais recentes como o de Caldas et al. (2019) o extrato de alho inibiu o crescimento da bactéria testada em todas as concentrações utilizadas pelo autor, em quanto o óleo essencial de alho não foi eficaz na inibição bacteriana em nenhuma concentração. Desta forma a atividade positiva do extrato in natura contra a inatividade do extrato aquoso comprovada nesse estudo corrobora com as informações já publicadas sobre a variedade nos resultados relativos ao tipo de extrato utilizado. 
No estudo realizado por Milani et al. (2016), os resultados da metodologia em poço foram superiores aos resultados da metodologia em disco, sendo o halo de inibição para S. aureus através do poço maior que o dobro do halo apresentado pela metodologia de disco. No teste feito em Candida albicans o halo também foi maior na metodologia de poço, sendo $10 \mathrm{~mm}$ a mais que o halo do antifúngico e do disco.

Neste estudo, a diferença nos resultados em relação à metodologia também é evidenciada, visto que o a metodologia de poço apresenta halos bem mais proeminentes que na metodologia de disco, já em relação aos controles, as zonas de inibição apresentadas pelo poço são maiores em até $50 \%$ que os apresentados pelos antibióticos de controle em S. aureus e S. pyogenes.

No estudo de Julinhaque, Soares e Campognoli (2019) o antifúngico Clorexidina apresentou zona de inibição de 12,6 $\mathrm{mm}$ em Candida spp. Nesse estudo o halo de inibição foi de $18 \mathrm{~mm}$ para clorexidina e o extrato in natura obteve halo de 24 $\mathrm{mm}$ na metodologia de poço, apesar do antibiótico apresentar halo maior que o da literatura apresentada, o extrato de alho ainda se sobressai sobre o controle, possuindo uma maior zona de inibição, desta forma é possível obervar a sensibilidade da Candida albicans ao extrato testado.

Muitos microrganismos são utilizados em pesquisas relacionadas, e os mais utilizados são Candida sp., S. aureus, e E. coli. (Milani et al., 2016; Caldas et al., 2019; Grosso et al.,2013; Fonseca et al., 2014). Porém estudos com S. pyogenes são escassos, sendo, portanto, os resultados desse trabalho sobre ação inibitória do alho em S. pyogenes um colaborativo aos possíveis tratamentos contra essa bactéria.

\section{Conclusão}

De acordo com resultados obtidos, o extrato aquoso do alho não obteve ação contra os microrganismos testados, entretanto o extrato in natura do alho (Allium sativum) conseguiu inibir significativamente o crescimento bacteriano e fúngico, em todos os microrganismos testados, corroborando desta forma para os estudos que também comprovam a ação antimicrobiana do alho (Allium sativum). O halo de inibição do extrato in natura tanto na metodologia de poço como de disco em S. aureus e em S. pyogenes foi superior ao halo dos antibióticos testados, mostrando desta forma como os microrganismos estão sensíveis ao extrato in natura do alho em comparação a os antibióticos comumente utilizados. O fato do extrato in natura possuir atividade contra $S$. pyogenes é interessante, pois esta não possui testes e pesquisas realizadas frequentemente como os demais microrganismos, o que contribui no incentivo de pesquisas mais aprofundadas para possíveis formas de se combater essa bactérias. Os resultados incentivam pesquisas futuras em outros microrganismos de importância médica devido a sua incidência e infecções que podem causar.

\section{Referências}

Milani, H. L. A., Teixeira, A. X. V., Sousa, E. C., Abreu, V. A., \& Ninahuaman, M. F. M. L. (2016). Avaliação da atividade antimicrobiana in vitro do alho (allium sativum) in natura. Acta Scientiae Biological Research, 1(1), 47-58.

Brouwer, S., Barnett.T.C.,Rivera-Hernadez, T., Rohde, M., \& Walker, M. J. (2016). Streptococcus pyogenes adhesion and colonization. FEBS LettersA, Australia590, 3739-3757.

Caldas, F. F. Filho, J. P. S., Rodrigues, C. A. R., \& Diego, P. da S. (2019). Atividade antimicrobiana do alho (Allium sativum l.) frente à bactéria causadora de infecção do trato urinário. Journal of Biotechnology and Biodiversity, Tocantins, 7, 217-224.

Colombo, A. L., \& Guimarões, T. (2003). Epidemiologia das infecções hematogênicas por Candida spp. Revista da Sociedade Brasileira de Medicina Tropical, Uberaba, 36, 599-607.

Machado, C. C., Silva, P. A., Souza, J. F., \& Souza, A. C. F. (2019). Efeito do extrato aquoso de alho Allium sativum L. sobre a atividade antibacteriana de antibióticos utilizados contra Staphylococcus aureus. Revista Arquivos Científicos (IMMES), 2(2), 111-118.

Dutra, F. S. G., Motta, O. V., Pereira, S. M. F., Carlos, L. de A., \& Vianna, A. P. (2016). Atividade Antimicrobiana De Extratos Vegetais Frente à Bactérias De Importância Médica. Biológicas \& Saúde, Campo dos Goytagazes, 6, 1-13.

Felix, A. L. M., Medeiros, I. L., \& Medeiros, F. D. (2018). Allium Sativum: Uma Nova Abordagem Frente a Resistência Microbiana: Uma Revisão. Bases conceituais da saúde 7, 107-112. 
Research, Society and Development, v. 10, n. 7, e10610716206, 2021

(CC BY 4.0) | ISSN 2525-3409 | DOI: http://dx.doi.org/10.33448/rsd-v10i7.16206

Ferreira, J. A., Ferreira, D. N., Lima, C. L. B., Fernandes, I. S., Júnior, L. P. de S., Swerts, M. C., Souza, S. C. A., \& Resende, J. C. de P. (2016). Eficiência da ação antimicrobiana do óleo essencial de alho (Allium sativum). PUC Minas, 5, 102.

Fiedler, T., Köller, T., \& Kreikemeyer, B. (2015). Streptococcus pyogenes biofilms-formation, biology, and clinical relevance. Frontiers in Cellular and Infection Microbiology. 5, 1-11.

Fonseca, G. M. Passos, T. C., Ninahuaman, M. F. M. L., Caroci, A. S., \& Costa, L. S. (2014). Avaliação da atividade antimicrobiana do alho (Allium sativum Liliaceae) e de seu extrato aquoso. Revista brasileira de plantas medicinais, 16, 679-684.

Gonçalves, M. V. DE F., Raimundo, N. G. F. F., Rita de Cássia, C. M., Jenilson ,L.B., Flávio, D., \& Cinara, V. P. (2015) .O alho e seus benefícios terapêuticos. Centro Universitário Quixabá,[MB1] Quixadá, 2, 1,

Grosso, E. de S. B, Ana, P. L. L, Ferreira, G., Andrade, M. C., \& Oliveira, A. P. (2013). Efeito antimicrobiano do alho (allium sativum) sobre cepas de staphylococcus aureus e escherichia coli isoladas de pacientes de um hospital escola do Sul de Minas. $13^{\circ}$ Congresso Nacional de Iniciação Científica, 1,7 .

Johnson, M., Olaleye, O., \& Kolawole, (2016). O Antimicrobial and Antioxidant Properties of Aqueous Garlic (Allium sativum) Extract against Staphylococcus aureus and Pseudomonas aeruginosa. British Microbiology Research Journal, 141-11.

Julinhaque, T. A., Soares, N. L., \& Campagnoli, E. B. (2019). Avaliação in vitro da eficácia da saliva artificial contendo lisozima, lactoferrina e lactoperoxidase frente a leveduras candida spp. XXVIII Encontro anual de Iniciação Cientifica Junior. [s.n.]. Paraná.

Saraiva, S. R. G. L., Saraiva, H. C. C., de Oliveira-Júnior, R. G., Silva, J. C., Damasceno, C. M. D., da Silva Almeida, J. R. G., \& Amorim, E. L. C. (2015). A implantação do programa de plantas medicinais e fitoterápicos no sistema público de saúde no brasil: uma revisão de literatura. Revista Interdisciplinar de Pesquisa e Inovação, 1(1).

Moreno, R. L. S. (2019). Avaliação da atividade antimicrobiana in vitro de óleo essencial de alho sobre bactérias patogênicas. Artigos Científicos- AC\&T, [MB2] 1-9.

Ostrosky, E. A., Mizumoto, M. K., Lima, M. E., Kaneko, T. M., Nishikawa, S. O., \& Freitas, B. R. (2008). Métodos para avaliação da atividade antimicrobiana e determinação da concentração mínima inibitória (CMI) de plantas medicinais. Revista Brasileira de Farmacognosia, 18(2), 301-307.

Qin, L., Da, F., Fisher, E. L., Tan, D. C., Nguyen, T. H., Fu, C. L., \& Otto, M. (2017). Toxin mediates sepsis caused by methicillin-resistant Staphylococcus epidermidis. PLoS pathogens, 13(2), e1006153.

Salem, M. L. O., Ghaber, S. M., Baba, S. E. W. O., \& Maouloud, M. M. O. (2016). Sensibilité aux antibiotiques des souches destaphylococcus aureus communautaires dans la région de Nouakchott (Mauritanie). The Pan African Medical Journal, 24.

Santos, A. L. D., Santos, D. O., Freitas, C. C. D., Ferreira, B. L. A., Afonso, I. F., Rodrigues, C. R., \& Castro, H. C. (2007). Staphylococcus aureus: visitando uma cepa de importância hospitalar. Jornal Brasileiro de Patologia e Medicina Laboratorial, 43(6), 413-423.

Silva, A. J. (2019). Avaliação da Atividade Antimicrobiana De Óleos Essenciais Obtidos De Diferentes Fabricantes. Sinapse Múltipla, 8, 33-40. 